\title{
Make applied phenomenology what it needs to be: an interdisciplinary research program
}

\author{
Matthew Burch ${ }^{1}$ D
}

Accepted: 2 February 2021 / Published online: 13 July 2021

(C) The Author(s) 2021

\begin{abstract}
Once a marginal affair, applied phenomenology is now a vast and vibrant movement. With great success, however, comes great criticism, and critics have been harsh, accusing applied phenomenology's practitioners of everything from spewing nonsense to assailing down-to-earth researchers with gratuitous jargon. In this article, I reconstruct the most damning criticisms as a dilemma: Either applied phenomenology merely describes experience, in which case it offers nothing distinctive, or it involves the kind of analysis characteristic of classical phenomenology, in which case it's only of interest to a small number of philosophers; either way, we should explore the experiential dimension by other means. Notwithstanding the enormous body of research in applied phenomenology, few authors have tried to explain what makes it an independent intellectual enterprise distinct from pure phenomenology, and none has defused this dilemma. Here I try my hand at both. After considering eight major approaches to applied phenomenology that fail to defuse the dilemma, I propose an approach that, I argue, does the job, one that understands applied phenomenology as a research program that brings the phenomenological method and the resources of at least one other discipline to bear on problems beyond the scope of any monodisciplinary approach.
\end{abstract}

Keywords Phenomenology · Applied phenomenology · Phenomenological method · Interdisciplinarity · Qualitative research

\section{Introduction}

While enjoying a recent rise in popularity, applied phenomenology (henceforth AP) has also suffered a spate of searing attacks. Critics like Jonathan Sholl accuse phenomenologists of launching borderline-ignorant broadsides against naturalism,

Matthew Burch

mburch@essex.ac.uk

1 School of Philosophy and Art History, Interdisciplinary Studies Centre, University of Essex, Wivenhoe Park, CochesterEssex CO4 3SQ, UK 
while failing to furnish any results not already offered by psychology and its subfields. ${ }^{1}$ Others go further still and claim that AP has risen to prominence on hot air, i.e., jargon-laced gas that obscures the emptiness of its claims and the arbitrariness of its methods. ${ }^{2}$ Criticisms are no less rancorous within the ranks of AP's practitioners, where major figures like Max van Manen and Jonathan Smith question the phenomenological credentials of each other's work. ${ }^{3}$

What should we make of this? Does AP really offer nothing distinctive? Are its claims vacuous and its methods haphazard? Should we abandon the practice and explore the experiential dimension by other means? That would be hasty, as the above criticisms only have bite against certain versions of AP.

In saying this, however, I by no means intend to accuse critics of knowingly attacking a straw man. To the contrary, the major misunderstandings at issue here stem, in large part, not from AP's critics but rather from three other sources that feed into their work. First, the story of phenomenology, as Ricoeur famously puts it, reads like a "history of Husserlian heresies", with each major figure taking up Husserl's method only to redefine it in some supposedly fundamental way. ${ }^{4}$ According to some, this has left phenomenology a fractured discourse with no shared aims or methods. Secondly, to dodge longstanding concerns about phenomenology's transcendental aspirations, some phenomenologists confine themselves to nothing more than the 'careful first-person description of experience', which indeed makes their approach seem indistinguishable from other descriptive research methods. Finally, analytic philosophy of mind has inadvertently muddied the waters further by using the term phenomenology as a synonym for phenomenality, an equivalence that phenomenologists rejected early on, as it often reduces phenomenology to the unphilosophical activity of introspecting one's private mental states. ${ }^{5}$ These three trends all court confusion about what phenomenology is.

The ambiguity multiplies in AP. Not only does confusion from the above sources seep into the applied discourse but, to make matters worse, in many cases authors simply cherry-pick terms from their favourite phenomenologists, without apparent concern for what makes those ideas phenomenological, as if one does AP simply by co-opting terminology. What's more, very little work has been done to explain what makes AP a distinctive intellectual enterprise. What distinguishes AP from pure phenomenology? Few researchers have even tried to answer this question.

If we fail to pin down what we do when we do phenomenology, and we barely bother to distinguish AP from its pure counterpart, why should critics be anything but confused about what the tradition offers? As I see it, then, we owe AP's critics thanks for challenging the phenomenological community to specify what AP is and what makes it distinctive. This kind of clarificatory work matters. No physicist would tolerate me calling my careful descriptions of physical objects colliding in the

\footnotetext{
1 Sholl (2015).

2 Gergel (2012) and Paley (2017).

3 van Manen (2017a, 2017b) and Smith (2018).

4 Ricoeur (1987, p. 9).

5 For a helpful discussion of this, see the first chapter of Zahavi (2017).
} 
back garden "applied physics"; and none should. Authors working in AP owe their readers a substantive justification for using the term phenomenology and an explanation of what makes their practice distinctive. I try to meet those obligations here.

I proceed as follows. First, I reconstruct the most damning criticisms of AP as a dilemma. Next, I show why most of today's approaches to AP fail to escape this dilemma unscathed. Finally, to defuse the dilemma, I offer an account of AP as a research program that brings the phenomenological method and the resources of at least one other discipline to bear on problems beyond the scope of any monodisciplinary approach. To be clear, what I offer here is not a new way of doing AP but rather a new way of understanding what the best work in AP already does.

\section{A dilemma for AP}

We can construct our dilemma as follows:

1. If AP offers nothing but first-person descriptions of experience, then it offers nothing distinctive, and we should study the experiential dimension by other means.

2. If AP involves the kind of analysis characteristic of classical phenomenology, then its analyses are only of interest to a small group of philosophers, and we should study the experiential dimension by other means.

3. Either AP offers nothing but first-person descriptions of experience, or it involves the kind of analysis characteristic of classical phenomenology.

4. Therefore, we should study the experiential dimension by other means. ${ }^{6}$

The first horn of this dilemma captures the most common criticism of AP. Hostile outsiders like Sholl and Paley, sympathetic collaborators like Gergel, and critical insiders like Zahavi all raise this objection against a significant subset of AP's practitioners. ${ }^{7}$ Sholl offers a typical formulation: "it is not clear exactly how phenomenology's first-person emphasis is distinct from what one finds in psychology and its various subfields", and if that's so, then "the utility of their contributions become[s] unclear". 8 Why? Because phenomenological texts teem with confusing phraseology that psychology and its subfields do not inflict on us; what's more, phenomenology affords none of the sophisticated tools and techniques we find in contemporary empirical approaches for organising, codifying, synthesizing, and interpreting large amounts of first-person data. If phenomenology offers nothing distinctive, why should we prefer its purple prose to the promising tools and techniques of more straightforward empirical approaches? Call this the 'distinctiveness' horn of the dilemma.

\footnotetext{
${ }^{6}$ To my knowledge, no one formulates their objections to AP in terms of this dilemma; but I think it's a useful way to present a cluster of well-known objections.

7 Sholl (2015), Paley (2017), Gergel (2012), and Zahavi (2019b, 2020, 2021).

8 Sholl (2015, p. 408; p. 400).
} 
The second horn of the dilemma is as old as phenomenology itself. Classically conceived, phenomenology has a transcendental dimension, as it concerns itself not so much with particular phenomena, but rather with the conditions of our making sense of phenomena. That's a distinctive offer: Neither psychology nor any of its subfields claims to do that. What's more, none of them would ever want to: After all, who cares about such abstruse, esoteric preoccupations outside a philosophy seminar? "No one," say many of phenomenology's critics. Call this the 'Who cares?' horn of the dilemma.

It's important to bear in mind that these horns work in tandem. If AP's practitioners evade the 'distinctiveness' horn by insisting on phenomenology's transcendental dimension, then they immediately face the 'Who cares?' horn. And if they steer clear of the latter by limiting themselves to merely describing experience from the first-person perspective, then they get impaled on the 'distinctiveness' horn.

\section{Dodges and impalements}

Before I assess how today's leading approaches to AP fare against this dilemma, I need to clarify something about my procedure. Notwithstanding an enormous body of research in AP, few authors try to explain what makes it an independent intellectual enterprise distinct from pure phenomenology. In this section, then, I make explicit several alternative approaches to AP that operate implicitly in some of today's leading applied phenomenological research. In total, I consider eight approaches. I collect the first six in two clusters, according to their shared vulnerabilities; the last two I evaluate independently.

The first cluster contains three contenders with a common vulnerability to the 'distinctiveness' horn. One contender resides at the intersection of the philosophy of mind and the cognitive sciences, in work that seeks to "naturalize phenomenology." Specifically, I have in mind work that takes phenomenological claims on board only insofar as those claims track with orthodox naturalism's two major commitments, namely, 1) the ontological commitment that only those entities posited by our best scientific theories are real, and 2) the methodological commitment that scientific investigation provides the only reliable means to acquire knowledge. This approach stands out among our contenders in that it sees AP as the only phenomenology worth doing. According to purveyors of this approach, the phenomenological method is nothing more than a "technique of introspection" that reveals "how things seem to us." 9 Thus, pure phenomenology is epistemically worthless, telling us nothing about the way things (scientifically or metaphysically) are. A certain kind of AP, however, is worth doing, namely, the work of feeding 'phenomenological data' into a broader scientific framework in order to build "a bridge — the bridge-between the subjectivity of human consciousness and the natural sciences." ${ }^{, 10}$ On this view, then, AP is the incorporation of 'phenomenological data' into a scientific image of the mind.

\footnotetext{
9 Dennett (1991, p. 44) and Noë (2007, p. 231).

10 Dennett (2007, p. 249).
} 
Our second contender comes from Max van Manen. While van Manen's research differs radically from our first contender, he works with a strikingly similar conception of phenomenology. Phenomenology, he tells us, pursues "insight into the phenomenality of lived experience," seeking to "let a phenomenon (lived experience) show itself in the way that it gives itself while living through it." 11 What makes van Manen's work applied? His recent response to Zahavi provides an answer: Some philosophers, he tells us, "write almost exclusively for other philosophers." while others write in an "accessible manner on topics and issues that are more likely to touch many of us". ${ }^{12}$ Placing himself in the latter camp, van Manen suggests two senses in which we can consider his work applied: (1) he writes for an audience of non-philosophers and (2) deals with topics relevant to everyday life. ${ }^{13}$

The third and final member of this cluster is Interpretative Phenomenological Analysis (or IPA). IPA is an idiographic approach to qualitative research that attempts to provide granular $n=1$ descriptions of "experiences as experienced for particular people," i.e., it aims to describe "experiences as they are lived by an embodied socio-historical situated person."14 Like the first two approaches, then, IPA conceives of phenomenology as the careful description of experience. In what sense is it applied? Like van Manen, IPA's authors (a) write for non-philosophers and (b) deal with topics relevant to everyday life. But we could also call their work applied in the sense that they (c) deal with comparatively specific questions within a given discipline because, unlike pure phenomenology, they do not study "the structure of the phenomenon itself" but rather the single "person's experience of the phenomenon and the sense they make of their experience." 15

How do the members of this first cluster fare against the dilemma? They all take a hit on the 'distinctiveness' horn: Every member of this cluster portrays phenomenology as nothing more than the careful description of experience, and there's nothing distinctive about that. Countless research paradigms carefully describe experience, and many of them also afford tools and techniques for sorting and synthesizing experiential data that phenomenology doesn't offer. The members of this cluster thus get impaled on the 'distinctiveness' horn.

What about the second horn? Although these authors boast impressive citation metrics, the relevant question vis-à-vis the 'Who cares?' horn isn't whether researchers in fact care about this work but rather whether they should. The answer to that latter question is straightforward: Since what these authors present as phenomenology offers nothing distinctive, to the extent that the value of their work hangs on its

\footnotetext{
11 van Manen (2017a, p. 779, 2017b, p. 813).

12 van Manen (2019, p. 2).

13 It's worth noting that these models for AP parallel attempts to conceptualize applied philosophy. So, for example, van Manen's approach to AP resembles both the "audience conception" and the "relevance conception" of applied philosophy. See Lippert-Rasmussen (2016) for a helpful taxonomy of approaches to applied philosophy.

14 Smith et al. (2009, p. 16) and Eatough and Smith (2017, p. 194).

15 Ibid. This understanding of AP resembles the "specificity conception" of applied philosophy (LippertRasmussen 2016).
} 
putatively phenomenological character, it warrants no special attention. ${ }^{16}$ In other words, to the extent that their work does nothing but describe the 'what-it's-like' dimension of experience, there's no good reason to prefer it to any other descriptive approach.

Turning now to the second cluster, its first member comes from the phenomenology of medicine (henceforth PM). The major research currents in PM coalesce around the claim that phenomenology provides an essential supplement to the biomedical approach: specifically, biomedical science studies health, disease, and illness strictly from the third-person perspective, which phenomenology supplements with first-person analyses of the experience of health and illness. Exactly which conception of phenomenology PM promotes is ambiguous. At times, its authors seem to follow the first cluster in reducing phenomenology to the careful description of experience. Other times, however, they declare phenomenology a "distinctly philosophical method... [that] investigates the conditions of possibility for having a particular experience."17 PM's status as an applied discipline is likewise ambiguous. Some of PM's authors seem to regard their work as pure phenomenology, in which case PM would drop from our list of viable approaches to AP. But its authors could also lay claim to another common conception of applied work, namely, using an established method to tackle topics not previously treated by a tradition. ${ }^{18}$

The second member of this cluster comes from Wayne Martin and Ryan Hickerson. Noting the bitter, longstanding disagreement over phenomenology's proper method, Martin and Hickerson set that dispute aside, defining phenomenology "not by its method but by its theoretical aims and by the range of objects with which it is concerned." "19 Ecumenical on the matter of method, then, they define phenomenology by its focus on "lived experience." ${ }^{20}$ Martin and Hickerson then go on to make one of few attempts to explicitly distinguish AP from its pure counterpart, declaring their work applied on the basis of "its intended practical import." ${ }^{21}$ For Martin and Hickerson, then, AP is research with an intended practical import that focuses on lived experience.

The final member of the second cluster, developed by Dan Zahavi, represents another one of the few efforts to distinguish AP from pure phenomenology. ${ }^{22} \mathrm{Criti}-$ cising authors who insist that AP deploy Husserl's "epoché" and the "phenomenological reduction," Zahavi exhorts researchers interested in phenomenology to ignore these methodological notions: "those who seek to practice applied phenomenology, i.e., those who seek to use phenomenological ideas in a non-philosophical context," he argues, need not "employ the epoché and the reduction if their work is

\footnotetext{
16 This doesn't apply to Dennett, then, since he has made multiple important, original intellectual contributions that in no way hang on his misuse of the term phenomenology.

17 Carel (2016, pp. 20-21).

18 This resembles the "methodology conception" of applied philosophy (Lippert-Rasmussen 2016).

19 Martin and Hickerson (2013, p. 196).

20 Ibid.

21 Ibid, p. 197.

22 Zahavi (2019a, 2019b, 2020, 2021).
} 
to qualify as phenomenological." 23 To do AP, rather, researchers need only employ "central phenomenological concepts." ${ }^{24}$ Phenomenology, Zahavi argues, is not just a method; it's also a collection of theoretical accounts that researchers can draw on to challenge the assumptions of their own respective fields. ${ }^{25}$ Thus, like Martin and Hickerson, Zahavi sets the matter of method aside, and claims that to practice AP, one need only apply central phenomenological ideas in a non-philosophical context.

How do these approaches fair against the dilemma? It depends. As we've just seen, all three leave the question of phenomenology's proper method fundamentally open-ended: PM vacillates between portraying phenomenology as the mere description of experience and as constitutive analysis; Martin and Hickerson's methodological ecumenicism likewise leaves room for work that merely describes experience and work that adheres to phenomenology's traditional methodological commitments; finally, Zahavi tells us that AP applies phenomenological ideas in a non-philosophical context, and so we can fairly assume that he's just as ecumenical about AP's method as Martin and Hickerson are. ${ }^{26}$ How these approaches fare against the dilemma, then, will depend on which resources practitioners happen to draw on. If, like the first cluster, they draw on texts that understand phenomenology as nothing but the careful description of experience, then they will take a hit from the 'distinctiveness' horn. On the other hand, if they draw on more traditional, properly phenomenological resources, they will survive the 'distinctiveness' horn only to face pressure from the 'Who cares?' horn.

What this means, then, is that we cannot definitively assess how these views fare against the dilemma, because none of them definitively distinguishes AP from pure phenomenology, i.e., none of them properly explains what warrants AP's status as an independent intellectual enterprise.

Say PM conceives of its work as applied in the sense that it uses the phenomenological method to tackle topics not previously treated by the tradition. On that conception, the only line between phenomenology and AP is something like an arbitrary cut-off date: "The tradition hasn't talked about X yet, so all work on X is applied." That's a shaky foundation for establishing AP as an independent intellectual enterprise. Say nothing were written on the phenomenology of grief before the cut-off. Would any phenomenological work on grief thereafter count as AP, even if in all relevant respects it resembles other phenomenological work on the emotions done before the cut-off? As I see it, then, the approach fails to offer a real distinction between phenomenology and AP.

Martin and Hickerson face a similar problem when they attribute AP its applied status on the basis of its "intended practical import." This implies that whether a given phenomenological analysis counts as applied hangs on how one intends to use

\footnotetext{
23 Zahavi (2021, p. 3; my emphasis).

24 Zahavi (2019b, p. 905).

25 Zahavi (2021, p. 13).

${ }^{26}$ Zahavi doesn't really adhere to ecumenicism in practice; for instance, he criticizes the work of van Manen and Smith as non-phenomenological, even though their work applies ideas from canonical phenomenological texts.
} 
it. But this fails to distinguish phenomenology from AP at all, since the same analysis can count as pure phenomenology when I intend it as a piece of theory, and as AP when I intend to put it to practical use.

Similarly, Zahavi conceptualizes AP as applied because it applies ideas from canonical phenomenological texts in a non-philosophical context, and this also fails to distinguish AP from pure phenomenology. Why is it applied phenomenology when I talk about 'the other' in the context of psychiatry or nursing, but good oldfashioned, pure phenomenology when I talk about 'the other as such', even if I draw on examples from psychiatry and nursing to illustrate my points? Because the latter happens in a philosophical context and the former doesn't? ${ }^{27}$ Changing context doesn't change what I'm doing sufficiently to warrant treating AP as an independent intellectual enterprise; there must be something distinctive about AP that warrants its independent status.

It's also worth highlighting a tension that arises from the methodological ecumenicism endorsed by Martin, Hickerson, and Zahavi. In various places, these authors rightly insist on the core phenomenological value of carefully attending to the phenomena and not prejudicing one's approach with pre-conceived theoretical baggage. But phenomenology's commitment to bracketing theories and attending to 'the things themselves' sits rather uneasily with their suggestion that we treat the phenomenological tradition itself as a collection of theories. It seems to say: bracket all your theories, except for phenomenological theories. But these authors cannot privilege phenomenological ideas this way, because they set aside the very thing that's meant to guarantee the non-prejudicial character of those ideas, namely, the phenomenological method.

Ultimately, I think the members of this cluster avoid questions of method as part of a broader strategy to manage the 'Who cares?' horn. As Zahavi expresses it, AP should not "hyper-philosophize" and force its audience to "choke on methodological metareflections," because this tends to alienate, intimidate, and confuse readers, and it does nothing to help researchers achieve their goals. ${ }^{28}$ Instead, AP should offer its audience access to the best phenomenological ideas without burdening them with abstruse philosophical reflections that they are poorly positioned to understand. This strikes me as a sensible strategy, but we should acknowledge its trade-offs, specifically, it leaves the border between phenomenology and AP poorly defined, and it fails to explain why researchers should feel entitled to draw freely on phenomenological theories while we insist they bracket other theories.

With these six views behind us, I want to turn now to what I consider the two most promising approaches to AP. The first comes from Anthony Fernandez, who frames the difference between pure and applied phenomenology as follows:

\footnotetext{
27 What's more, the notion of a non-philosophical context strikes me as problematic. First of all, it's almost impossible to get philosophers to agree on what philosophy is, so how can we determine what counts as a philosophical context? Secondly, assuming we know what philosophy is, it seems to me that if you're thinking philosophically, then you're in a philosophical context. Comparable intellectual work should not be deemed non-philosophical just because it's not done by professional philosophers, or because it's not published in a philosophy journal.

28 Zahavi and Martiny (2019, p. 161) and Zahavi (2021, p. 10),
} 
Phenomenology clarifies the constitutive features of human existence, which Fernandez, following Heidegger, calls 'existentials'; and AP studies the diverse manifestations (or 'modes') that these existentials instantiate across different populations. ${ }^{29}$ So, for example, mood is an existential-or a constitutive feature of human existence-studied by pure phenomenology; and particular moods, such as anxiety and joy, are modes of that existential studied by AP.

This elegant approach constitutes a significant advance in the AP literature. First, Fernandez unambiguously banishes the trivial, purely descriptive view of phenomenology from AP, framing his approach in terms of phenomenology's distinctive offer, as a discipline that studies the constitutive features of human existence. Thus, he neutralizes the 'distinctiveness' horn. Secondly, by conceptualising AP as the study of the modes that these constitutive features take across different populations, he avoids narrowing AP's purview to a domain that only interests a few philosophers. For instance, in a recent piece, Fernandez perspicuously demonstrates how his version of AP provides useful resources for a dimensional approach to psychiatric diagnosis. ${ }^{30}$ Finally, Fernandez is one of the few authors to recognize that we must make a sharp distinction between phenomenology and AP to warrant the latter's status as an independent intellectual enterprise.

I disagree, however, with the way Fernandez frames that distinction. For one thing, his proposal represents a revisionist take on the phenomenological tradition: If he's right, then classic analyses of phenomena such as anxiety, shame, mauvaise foi, and authenticity are not pure phenomenological analyses but rather products of AP. But this claim, I think, is not only revisionist; it also strikes me as incorrect. Consider Heidegger's account of 'authenticity.' As Fernandez rightly notes, authenticity is a mode of human existence. In the phenomenological analyses of the 'call of conscience' in Division II of Being and Time, Heidegger argues that the capacity to take responsibility for our existence (or to evade such responsibility) is a constitutive feature of human agency (or an 'existential'). Moreover, when I transparently act in light of that responsibility, I exhibit authenticity as a 'mode' of that existential; and when I evade that responsibility, I exhibit inauthenticity as a mode of that existential. ${ }^{31}$ Importantly, for our present purposes, Heidegger's accounts of authenticity and inauthenticity appeal to no evidence beyond what he relies upon in his phenomenological analysis of the existentials that make those modes possible, i.e., they all draw on first-person evidence that's in principle available to anyone. Although it's a mode, then, authenticity strikes me as a perfectly appropriate target for pure phenomenology. Correlatively, since it appeals to no extra-phenomenological evidence, I see no principled reason to consider the analysis of authenticity a piece of AP. So, although Fernandez rightly recognizes the need for a sharp distinction between phenomenology and AP, I think he draws the wrong distinction.

Our final contender points us towards a conception of AP that defuses the target dilemma, and thereby indicates the right way to distinguish phenomenology from

\footnotetext{
${ }^{29}$ Fernandez $(2017,2018)$. Fernandez elaborates the view with his co-author Allan Køster (2019).

30 Fernandez (2019).

31 For this interpretation of authenticity, see chapter 9 of Crowell (2013).
} 
AP. That conception emerges from the division of intellectual labour that Michael Wheeler devises for his 'Heideggerian cognitive science'. ${ }^{32}$ Specifically, Wheeler proposes that Heideggerian cognitive science should use the resources of phenomenology to provide a constitutive understanding of our being-in-the-world, while it draws on the cognitive sciences to furnish an enabling understanding of the causal mechanisms that give rise to our being-in-the-world. This approach, as I see it, points us towards what AP needs to be to function as an independent intellectual enterprise that defuses the target dilemma. By insisting on the distinctive, constitutive understanding afforded by phenomenology, it evades the 'distinctiveness' horn; and by providing solutions to problems that cannot be managed within the boundaries of a single discipline, it also neutralizes the 'Who cares?' horn. Moreover, Wheeler's approach demonstrates why work in AP warrants its status as an independent intellectual enterprise, namely, it answers questions that pure phenomenology could never answer on its own. Unlike the analysis of authenticity just discussed, questions regarding the causal enablers that give rise to our being-inthe-world cannot be answered by relying on the same evidence we use to develop a phenomenological account of our being-in-the-world. This, I contend, indicates the right way to distinguish between pure and applied phenomenology: The latter counts as an independent intellectual enterprise because it relies on evidence and/or methods unavailable to - and it solves problems that lie beyond the purview of - its pure counterpart. Although he never explicitly pitches it this way, Wheeler's work embodies an approach to AP that could defuse our target dilemma.

\section{Defusing the dilemma}

The account I develop in Sects. 4.1 and 4.2 can be seen as an attempt to formalize Wheeler's approach into a model of AP that practitioners can use not only in the cognitive sciences but across a wide range of disciplines. That model characterizes AP as a unique research program that (1) identifies interdisciplinary problems, (2) uses phenomenology to characterize the constitutive features of subjectivity implicated by those problems, and (3) integrates (2) with the findings and/or methods of some other discipline(s) to solve those problems.

Before I explicate the elements of this model, I want to emphasize that although none of the approaches considered in the previous section explicitly conceptualize AP in a manner that defuses the target dilemma, the last five contenders have all produced work in AP that escapes both horns unscathed. ${ }^{33}$ To reiterate, then, what I offer in this section is not a new way of doing AP but a new way of understanding what the best work in AP already does.

\footnotetext{
32 Wheeler (2005).

33 Zahavi, in particular, has done an incredible amount to advance AP, e.g., he and his co-author Shaun Gallagher wrote The Phenomenological Mind (2008), one of the most impactful works in AP, and the two of them also co-founded Phenomenology and the Cognitive Sciences, a journal that publishes much of the best work in AP.
} 


\subsection{Something distinctive?}

In the introduction, we noted that some scholars portray phenomenology as a fractured discourse with no shared research program. Without impugning that view's scholarly credentials, here I take sides with those who argue that all authentic phenomenological practice is united by a shared normative core. Call this core phenomenology (henceforth $\mathrm{CP}$ ) ${ }^{34} \mathrm{CP}$ is the study of meaning and its conditions of possibility by means of a reflective method that relies strictly on first-person evidence. CP's method is what makes AP a distinctive enterprise.

To understand CP, it helps to consider its founding motives. As Steven Crowell and Amie Thomasson discuss in detail, CP shares an origin story with analytic philosophy: both emerged in response to early $20^{\text {th }}$-century anxiety about the fate of philosophy after the breath-taking success of the natural sciences. ${ }^{35}$ What role remains for philosophy when the sciences become autonomous? Both traditions hit on the same basic answer: Whereas the sciences study natural objects and the regularities that govern them, philosophy studies meaning. Meaning, after all, is in no obvious sense a natural object amenable to scientific study; and yet it remains an ineliminable precondition of all inquiry, including scientific inquiry — for every inquiry presupposes the disclosure of a meaningful world investigated by the inquirer. Prescientific experience is not a chaotic flux of blooming, buzzing confusion that only becomes coherent under scientific scrutiny; rather, in everyday life, we dwell in an intelligible world that serves as base camp for our scientific voyaging.

Now, although both traditions turned towards meaning in response to philosophy's identity crisis, they did so differently. As Michael Dummett tells the story, early analytic philosophers focused on linguistic meaning, while Husserl's phenomenology extended the notion of Sinn to all intentional acts, linguistic or otherwise. ${ }^{36}$ For the phenomenologist, then, experience is meaningful all the way down: Every experience is an experience of something as something, and it's this ubiquitous experiential meaning - the so-called 'as-structure' of experience-that $\mathrm{CP}$ clarifies. How does it do so?

Once again, a contrast with science proves instructive. Science seeks what John McDowell calls "enabling understanding," i.e., it explains reality in causal terms, identifying the underlying causal enablers of observable phenomena and the laws that govern those enablers. Thus, science articulates what Wilfrid Sellars calls the "space of causes" and the "scientific image" of humanity. Phenomenology, on the other hand, is not an explanatory enterprise but a clarificatory one. Instead of enabling understanding, it pursues constitutive understanding - an articulation of the

\footnotetext{
${ }^{34}$ Many prominent contemporary phenomenologists endorse this basic conception of CP. Steven Crowell, in particular, is associated with the view that what unites the seemingly heterogenous phenomenological tradition is the "'reduction' from our ordinary concern with entities, being, the 'world,' to the meaning at issue in such concern" (Crowell 2019, 229-230). For other work broadly on board with this view, see Carr (1999), Drummond (1990), McMullin (2013, 2019), Thomasson (2019), Wheeler (2005) and Zahavi (2017).

${ }^{35}$ Crowell (2002) and Thomasson (2007).

${ }^{36}$ Dummett (1993).
} 
aspects of human subjectivity that allow us to constitute phenomena as the kind of phenomena they are. To be clear, we constitute phenomena not in the sense that we make them; rather, our subjectivity allows us to make sense of phenomena in a determinate way. The world we encounter always makes sense to us in some determinate way: everything I experience spontaneously presents itself as meaningful, $a s$ this or that kind of phenomenon. And CP clarifies the constitutive features of subjectivity through which phenomena are given to us as something determinate. Thus, $\mathrm{CP}$ is rightly considered a branch of transcendental philosophy, as it analyses the preconditions of sense. Unlike natural science, then, which makes first-order claims about objects in the space of causes, CP is a second-order, reflective enterprise that articulates the features of subjectivity that make it possible for us to occupy what Crowell, playing on Sellars's language, aptly calls the "space of meaning." 37

Research in CP, it's important to note, is correlational research. Phenomena always make sense - as this or that kind of phenomenon, in this or that mode of givenness - in relation to the features of our subjectivity. For example, the chair across from me presents a particular profile from a certain angle which makes an implicit reference to my perceptual capacities, bodily posture, and spatial position; at the same time, I intend the chair as having profiles not currently visible, which implicitly refers to my ability to explore the world with my body; what's more, the fact that I spontaneously encounter the chair as a chair makes implicit reference to the cultural know-how I possess in virtue of belonging to a shared social world; and so on. CP studies the myriad layers of these correlations between features of our subjectivity and the determinate way phenomena make sense to us.

CP makes this correlation thematic via a reflective method that involves a shift in attention. In everyday life, for the most part, I simply consider what's in front of me, focusing on the first-order characteristics of entities and others. To analyse my experience phenomenologically, however, I have to shift my attention, broadening my perspective to consider a wider framework of meaning-one that attends not only to the phenomena before me but also to aspects of my own subjectivity in virtue of which I experience these phenomena in this determinate way.

To illustrate this shift with an example, say I have an appointment with a student. In an ordinary, everyday attitude, when I meet her, I will simply attend to her first-order characteristics. To analyse the experience phenomenologically, however, I must shift my attention, taking in not only her first-order characteristics but also the broader framework of meaning in virtue of which she shows up to me precisely as she does. That broader framework will include, for example, the practice of education, a practice that, broadly construed, consists of a range of purposive activities organized around our interests in improving our epistemic practices and sharing knowledge. And it is only in virtue of the position my student occupies in that practice that I can experience her as a student. But it's not the mere fact that the practice of education exists that allows me to experience her as a student; it's also my sensitivity to the normative expectations of the practice that makes that possible. In other words, to experience her as a student, I need to be sufficiently socialized

${ }^{37}$ Crowell (2001, p. 5). 
into the practice to be able to relate to her in terms of its normative expectations. What's more, for me to experience her as a student, I also have to commit, in that very experience, to participating in the practice and seeing myself in its terms. I not only have to be sensitive to the normative expectations of the practice, then; I also have to commit to understanding my current experience in terms of those expectations. I have to relate to my student and the situation in terms of my commitments as a teacher.

Of course, the larger point here is that these claims hold not only of experiencing someone as a student; rather, it purports to identify constitutive features of subjectivity that underwrite meaningful experience in general: We make sense of phenomena as this or that kind of phenomenon in virtue of our sensitivity to the normative expectations of shared social practices and our real-time commitment to understanding ourselves in terms of those normative expectations. I can't defend these claims fully here, nor do I have space to identify the many other aspects of subjectivity at work in the constitution of meaningful experience. My goal, however, was only to illustrate how CP's method works: In a phenomenological attitude, we widen our attention to reflect not just on phenomena but also on our own sense-making capacities that enable us to encounter them as the determinate phenomena they are.

My approach to AP stays safe from the 'distinctiveness' horn, then, by relying explicitly on CP. No empirical approach to experience provides this kind of analysis. As we've seen, however, relying on CP immediately puts me under pressure from the 'Who cares?' horn. Why should anyone outside a small circuit of philosophy conferences care about such considerations?

\subsection{Something worth doing?}

At the end of section three, we took a cue from Wheeler and suggested that the answer to this question lies in AP's interdisciplinary character. ${ }^{38}$ And I proposed that we understand AP as a research program that (1) identifies an intrinsically interdisciplinary problem, (2) uses CP to characterize the constitutive features of subjectivity implicated by that problem, and (3) integrates (2) with the findings and/or methods of some other discipline(s) to solve the target problem. This keeps AP continuous with the phenomenological tradition, because it relies on CP's distinctive method; but it also justifies AP's status as an independent enterprise, because it relies on methods and research results unavailable to $\mathrm{CP}$ and tackles problems beyond CP's purview. Implicit in this approach to AP are the following commitments:

(1) A commitment to doing problem-driven work: Every project in AP should tackle a problem that (a) lacks a monodisciplinary solution and (b) becomes more tractable once we bring the resources of $\mathrm{CP}$ and some other discipline(s) to bear on it.

\footnotetext{
38 This resonates with a tradition that understands applied philosophy in terms of its "essentially interdisciplinary nature" (Stevenson 1970, p. 263).
} 
(2) A commitment to minimizing technical jargon that might alienate researchers from other disciplines.

(3) A commitment to offering something valuable to practitioners of other disciplines and/or professionals and stakeholders potentially impacted by their research.

Adhering to these commitments, I contend, should make work in AP worth doing and thereby defuse the target dilemma by neutralizing the 'Who cares?' horn.

To illustrate how this approach works in practice and why it should be of interest to people outside a narrow group of philosophers, I'll dedicate the rest of this section to an example. For heuristic purposes, I'll speak of AP as a three-step process:

Step 1: Identify a challenging interdisciplinary problem.

Step 2: Use CP to characterize the constitutive features of subjectivity implicated by that problem.

Step 3: Integrate step 2's results with the findings of some other discipline(s).

To begin with the first "step,"take as our interdisciplinary problem the development of a comprehensive approach to decision making under risk. I have no intention of solving that problem here, of course; I only want to sketch how AP might contribute towards such a solution.

Today's dominant approaches to this problem argue that risk is an intrinsically probabilistic affair and so the only normatively correct standards for rational risk decisions rely strictly on some version of probability theory. ${ }^{39}$ Probability theories divide into two main camps: subjective and objective. ${ }^{40}$ Both conceptualize risk mathematically, adhere to the basic consistency rules of probability calculus, and represent every risk event as bearing a definite value from 0 to 1 . For both camps, then, the risk of $R_{1}$ is greater than the risk of $R_{2}$ just in case $R_{1}$ is more probable than $\mathrm{R}_{2}$. The camps divide, however, over the question of what risk is. Subjective approaches conceive of risk as the measure of an agent's coherent degree of belief (or 'credence') that a risk event will occur. Objective approaches, on the other hand, conceive of risks as independent of what anyone believes. The dominant objective approach is the relative frequency (or frequentist) interpretation, according to which risk is the rate of occurrence of some risk event in a given reference class.

Neither probabilistic approach, however, can serve as a comprehensive guide to risk decisions, because neither affords sufficient guidance for singular risk decisions, i.e., one-off decisions that aim to manage the risks associated with a single decision made by (or on behalf of) one person in a specific set of circumstances at a particular time. As John Oberdiek has recently argued, neither subjective nor objective approaches provide well-intentioned agents sufficient guidance for making such decisions. ${ }^{41}$ Subjective approaches offer practical but

\footnotetext{
39 Slovic et al. (2004).

40 Carnap (1945).

41 Oberdiek (2017).
} 
insufficiently normative guidance: Their guidance is practical because the agent only needs to consult her own beliefs to arrive at a determinate assessment of the relevant probabilities; but their guidance is insufficiently normative for the same reason. If two people have different priors about event $\mathrm{E}$, the subjective approach offers no normative basis to adjudicate their disagreement. It promises that their assessments will converge 'in the long run', but that won't help us make a singular risk decision now. The objective approach, on the other hand, provides guidance that is normative but impractical. Its guidance is normative, because it is objective; but it is impractical for at least two reasons. First, there is the "single case problem": Since frequentism defines risk as the relative frequency of some risk event $\mathrm{E}$ in reference class $\mathrm{C}$, it cannot provide guidance for decisions that involve unique risk events, because in a reference class with 1 member, the only possible values for $\mathrm{E}$ are 0 or 1 . What's more, every event is arguably unique. Secondly, there is "the reference class problem": For any risk event E, we can assign E to any number of reference classes in which the relative frequency of E differs; thus, frequentist risks are objective but indeterminate. Probabilistic approaches cannot offer a comprehensive approach to decision making under risk, then, because they cannot guide our singular risk decisions.

Here we begin "Step 2" of our AP analysis. Which constitutive features of subjectivity are implicated by our target problem? Put otherwise, what are the aspects of subjectivity in virtue of which we experience something as a risk? According to some proponents of today's dominant risk theories, this is not a helpful question, because the term 'risk' just means 'probability'. This claim, however, obscures the phenomenological constitution of risk. To see why, imagine the following scenarios:

Scenario1: There's a 0.75 probability that in ten minutes a nuclear explosion will occur in a vacuum in some distant region of space, affecting no living organisms, now or ever.

Scenario2: There's a 0.75 probability that in ten minutes an explosion of the same magnitude will occur in a densely populated city.

Although the relevant probabilities are identical, it would be obtuse to claim that these scenarios pose the same risk; indeed, it's unclear that scenario ${ }_{1}$ poses any risk. Why? Because to experience some future event $\mathrm{E}$ as a risk, I have to experience $\mathrm{E}$ as a posing a significant chance of a setback to someone's interests. Phenomena that do not threaten anyone's interests do not show up as risks. What's more, as agents, our interests are those things that matter to us and in which we have a stake, and so there is an essential correlation between our interests and what we care about. Our cares shape our interests, and our interests reflect our cares. Given this risk-interestcare connection, then, we can say that it is only in virtue of our cares that we can experience phenomena as risks. An event can only show up as a risk for someone in light of what she cares about. Our cares, then, are among the constitutive features of subjectivity implicated by the problem of singular risk decisions.

Turning now to "Step 3," I want to propose that AP provides a promising way to think about a comprehensive approach to decision making under risk. Such 
a framework would acknowledge the value of probabilistic approaches for managing all sorts of risk decisions at the population and policy level. However, it would draw on phenomenological resources to tackle the practical and normative difficulties associated with singular risk decisions. Since one cannot merely rely on one's subjective 'credence' about the probability of some outcome, nor can one simply refer to risk frequencies to make a call, one must instead engage in a fine-grained analysis of what this particular individual cares about and what is in this particular individual's interests. At the end of the day, then, the decision will not only involve considerations of likelihood but also fundamentally normative questions about what matters to this person and what is in her best interests (considered in light of what she cares about); and a CP analysis of our cares and interests could help us better understand how such decisions are-and should be-made.

Of course, I've only just sketched the approach here, but it should suffice to illustrate how work in AP could evade the 'Who cares?' horn and thereby defuse the dilemma. Specifically, it shows how work in AP could (1) identify a challenging interdisciplinary problem, namely, developing a comprehensive approach to decision making under risk; (2) use CP to characterize the constitutive features of subjectivity implicated by that problem, i.e., our cares and interests as agents; and (3) integrate (2) with probabilistic theories of risk to build a more comprehensive approach to the problem identified in (1). Such an approach could make a valuable contribution not only to AP but also to practitioners of other disciplines and the professionals and stakeholders who make risk decisions on a daily basis.

\section{Conclusion}

This article reconstructed prominent criticisms of AP as a dilemma: Either AP merely offers first-person descriptions of experience, or it involves the constitutive analysis characteristic of $\mathrm{CP}$; in either case, we're better off studying the experiential dimension by other means. I then argued that many prominent contemporary conceptions of AP get impaled by this dilemma, and I offered a new conception of AP as a research program that integrates $\mathrm{CP}$ with the method and/or findings of some other discipline(s) to solve problems for which no monodisciplinary solution suffices. My approach to AP defuses the target dilemma: It stays safe from the 'distinctiveness' horn, because it relies on CP; and it survives the 'Who cares?' horn, because it solves interdisciplinary problems of interest to academics, professionals, and stakeholders across a variety of theoretical and practical contexts.

At the outset of this paper, I said that the clarificatory work undertaken here matters because AP owes its critics answers. By defusing the dilemma, we have answered their most damning criticisms. This work also matters, however, because right now there's a lot of excellent research being done in AP, but we lack any consensus about the shared aims and methodological commitments of such work. It's important to clearly explain what we do when we do AP, then, not only to answer AP's critics but also to establish a shared research program around which practitioners can gather to do their vital work. Today we face many interdisciplinary 
challenges to which AP could make key contributions; but to do so well, AP's practitioners need to operate with a clear sense of precisely what kind of contribution they stand to make. I hope we continue this conversation and make applied phenomenology what it needs to be: an interdisciplinary research program that puts core phenomenological analyses of the constitutive features of subjectivity into conversation with other disciplines to solve real-world problems.

\section{Funding N/A.}

\section{Compliance with ethical standards}

Conflicts of interest The author declares that they have no conflict of interest.

Open Access This article is licensed under a Creative Commons Attribution 4.0 International License, which permits use, sharing, adaptation, distribution and reproduction in any medium or format, as long as you give appropriate credit to the original author(s) and the source, provide a link to the Creative Commons licence, and indicate if changes were made. The images or other third party material in this article are included in the article's Creative Commons licence, unless indicated otherwise in a credit line to the material. If material is not included in the article's Creative Commons licence and your intended use is not permitted by statutory regulation or exceeds the permitted use, you will need to obtain permission directly from the copyright holder. To view a copy of this licence, visit http://creativecommons.org/licen ses/by/4.0/.

\section{References}

Carel, Havi. 2016. Phenomenology of illness. Oxford: Oxford University Press.

Carnap, Rudolf. 1945. The two concepts of probability: The problem of probability. Philosophy and Phenomenological Research 5 (4): 513-532.

Carr, David. 1999. The paradox of subjectivity: The self in the transcendental tradition. New York: Oxford University Press.

Crowell, Steven Galt. 2001. Husserl, heidegger, and the space of meaning: Paths towards transcendental phenomenology. Evanston, Illinois: Northwestern University Press.

Crowell, Steven Galt. 2002. Is there a phenomenological research program? Synthese 131 (3): 419-444.

Crowell, Steven Galt. 2013. Normativity and phenomenology in Husserl and Heidegger. Cambridge: Cambridge University Press.

Crowell, Steven Galt. 2019. A philosophy of mind: Phenomenology, normativity, and meaning. In Normativity, meaning, and the promise of phenomenology, eds. Matthew Burch, Jack Marsh, and McMullin, Irene, 329-54. London: Routledge.

Dennett, Daniel. 1991. Consciousness explained. Brown and Company: Little.

Dennett, Daniel. 2007. Heterophenomenology reconsidered. Phenomenology and the Cognitive Sciences 6 (1): 247-270.

Drummond, John. 1990. Husserlian intentionality and non-foundational realism: Noema and object. Kluwer Academic Publishers.

Dummett, Michael. 1993. The origins of analytical philosophy. London: Bloomsbury.

Eatough, Virginia, and Jonathan A. Smith. 2017. Interpretative phenomenological analysis. In Handbook of qualitative research in psychology, eds. Carla Willig and Wendy Stainton Rogers, 193-209. London: Sage Publication, Ltd.

Fernandez, Anthony Vincent. 2017. The subject matter of phenomenological research: Existentials, modes, and prejudices. Synthese 194 (9): 3543-3562. 
Fernandez, Anthony Vincent. 2018. Beyond the ontological difference: Heidegger, Binswanger, and the future of existential analysis. In Existential medicine: Essays on health and illness, ed. Kevin Aho, 27-42. New York: Rowman and Littlefield International.

Fernandez, Anthony Vincent. 2019. Phenomenology and dimensional approaches to psychiatric research and classification. Philosophy, Psychiatry, and Psychology 26 (1): 65-75.

Fernandez, Anthony Vincent, and Allan Køster. 2019. On the subject matter of phenomenological psychopathology. In The Oxford handbook of phenomenological psychopathology, eds. Giovanni Stanghellini, Matthew Broome, Andrea Raballo, Anthony Vincent Fernandez, Paolo Fusar-Poli, and René Rosfort. Oxford: Oxford University Press.

Gallagher, Shaun, and Dan Zahavi. 2008. The phenomenological mind. Routledge.

Gergel, Tania L. 2012. Medicine and the individual: Is phenomenology the answer? Journal of Evaluation in Clinical Practice 18 (5): 1102-1109.

Lippert-Rasmussen, Kasper. 2016. The nature of applied philosophy. In A Companion to applied philosophy, eds. Kasper Lippert-Rasmussen, Kimberley Brownlee, and David Coady, 1-17. Wiley-Blackwell.

Martin, Wayne, and Ryan Hickerson. 2013. Mental capacity and the applied phenomenology of judgement. Phenomenology and the Cognitive Sciences 12 (1): 195-214.

McMullin, Irene. 2013. Time and the shared world: Heidegger on social relations. Evanston, Illinois: Northwestern University Press.

McMullin, Irene. 2013. 2019. Existential flourishing: A phenomenology of the virtues. Oxford: Oxford University Press

Noë, Alva. 2007. The critique of pure phenomenology. Phenomenology and the Cognitive Sciences 6 (1): 231-245.

Oberdiek, John. 2017. Imposing risk: A normative framework. Oxford: Oxford University Press.

Paley, John. 2017. Phenomenology as qualitative research: A critical analysis of meaning attribution. London: Routledge.

Ricoeur, Paul. 1987. A l'école de la phénoménologie. Paris: Vrin.

Sholl, Jonathan. 2015. Putting phenomenology in its place: Some limits of a phenomenology of medicine. Theoretical Medicine and Bioethics 36 (6): 391-410.

Slovic, Paul, Melissa L. Finucane, Ellen Peters, and Donald G. MacGregor. 2004. Risk as analysis and risk as feelings: Some thoughts about affect, reason, risk, and rationality. Risk Analysis 24 (2): 311-322.

Smith, Jonathan A. 2018. Yes it is phenomenological: A reply to Max Van Manen's critique of interpretative phenomenological analysis. Qualitative Health Research 28 (12): 1955-1958.

Smith, Jonathan A., Paul Flowers, and Michael Larkin. 2009. Interpretative phenomenological analysis: Theory, method and research. London: Sage.

Stevenson, Leslie. 1970. Applied philosophy. Metaphilosophy 1 (3): 258-267.

Thomasson, Amie L. 2007. Conceptual analysis in phenomenology and ordinary language philosophy. In The analytic turn: Analysis in early analytic philosophy and phenomenology, ed. Michael Beaney, 270-284. New York: Routledge.

Thomasson, Amie L. 2019. What can phenomenology bring to ontology? Res Philosophica. 2019. https:// doi.org/10.11612/resphil.1760.

Van Manen, Max. 2017a. But is it phenomenology? Qualitative Health Research 27 (6): 775-779.

Van Manen, Max. 2017b. Phenomenology in its original sense. Qualitative Health Research 27 (6): 810-825.

Van Manen, Max. 2019. Rebuttal: Doing phenomenology on the things. Qualitative Health Research 29 (6): 908-925.

Wheeler, Michael. 2005. Reconstructing the cognitive world: The next step. Cambridge: Cambridge University Press.

Zahavi, Dan. 2017. Husserl's legacy: Phenomenology, metaphysics, and transcendental philosophy. Oxford: Oxford University Press.

Zahavi, Dan. 2019a. Phenomenology: The basics. London: Routledge.

Zahavi, Dan. 2019b. Getting it quite wrong: Van Manen and Smith on phenomenology. Qualitative Health Research 29 (6): 900-907.

Zahavi, Dan. 2020. The Practice of phenomenology: The case of Max van Manen. Nursing Philosophy 21 (2). https://doi.org/10.1111/nup.12276.

Zahavi, Dan. 2021. Applied phenomenology: Why it is safe to ignore the epoché. Continental Philosophy Review. https://doi.org/10.1007/s11007-019-09463-y. 
Zahavi, Dan, and Kristian MM. Martiny. 2019. Phenomenology in nursing studies: New perspectives. International Journal of Nursing Studies 93: 155-162.

Publisher's Note Springer Nature remains neutral with regard to jurisdictional claims in published maps and institutional affiliations. 